\title{
G6PD-Deficient Erythrocytes Count
}

National Cancer Institute

\section{Source}

National Cancer Institute. G6PD-Deficient Erythrocytes Count. NCI Thesaurus. Code C132368.

The determination of the amount of G6PD-deficient erythrocytes in a biological sample. 